\title{
Somos Todos 3868
}

\section{We Are All 3868}

Rui Tato MARINHO $\triangle 1$

Acta Med Port 2019 Mar;32(3):173-174 - https://doi.org/10.20344/amp.12021

Palavras-chave: Portugal; Publicação; Revistas

Keywords: Periodicals as Topic; Portugal; Publishing

\section{A ciência mais antiga. A revista médica mais antiga?}

A Acta Médica Portuguesa (AMP) nasceu há 40 anos. Um grupo de visionários fundou e criou condições para que o património científico médico ficasse disponível para sempre. Não sei se ser médico será a profissão mais antiga do Mundo, mas é decerto uma das mais antigas e mais místicas/mágicas. Claro que até há muito pouco tempo era revestida de muito pouca 'Medicina Baseada na Evidência'. ${ }^{1}$ Mas o nascimento da nossa AMP foi um marco muito importante. Durante muitos anos, era a única revista médica científica indexada em bases de dados internacionais (PubMed/MEDLINE).

O primeiro artigo, em 1979, teve autores muito ilustres que fariam história na Medicina Portuguesa, um deles um dos nossos bastonários, o Prof. Machado Macedo. ${ }^{2}$

Porque é que, dado ser tão difícil, a AMP conseguiu logo desde o primeiro número ser indexada? A razão parece residir no facto de representar um País e uma instituição de grande credibilidade e de âmbito nacional como é a Ordem dos Médicos.

Sim, são quase 4000 artigos, todos colocados na PubMed/MEDLINE, com conteúdo integral em versão PDF, com acesso muito fácil a partir da referência do artigo (Link-Out). É, pois, um património médico, social e científico, que ilustra de forma exemplar a evolução da Medicina e dos médicos em Portugal.

É uma cultura que temos que mudar de forma rápida, ou seja, passar a referenciar os nossos trabalhos científicos. Todos ganhamos com tal objetivo, dentro das regras editoriais.

\section{Que bom que foi ter sido Editor-Chefe da AMP}

Corria o ano de 2011 quando, inesperadamente como acontece em muitas ocasiões na vida, surge um convite do Bastonário José Manuel Silva para integrar a equipa como editor-chefe da AMP, "The Yellow Journal". Que honra! Mas depois de 11 anos sem editor-chefe efetivo... Um presente envenenado? Não me parecia! Quem sabia mais de edição médica em Portugal? Eram três: Helena Donato, Tiago Villanueva, Fernando Fernandez-Llimos. Este último, um Farmacêutico Espanhol, mas que tinha conseguido criar condições para que a nossa AMP tivesse pela primeira vez o tão almejado Fator de Impacto.

E fomos caminhando com o staff fixo da AMP que foi crescendo, o eterno Miguel Reis, o designer Rui Matos, a coordenadora Carla de Sousa, o João Massano, o próprio José Manuel Silva, o José Carona Carvalho, António Vaz Carneiro, a Manuela Oliveira, o Pedro Câmara Pestana, e muitos mais. The dream team, aprendemos muito uns com os outros. Aprendi muito também com as ideias do clássico Editor-Chefe do British Medical Journal (Richard Smith), com as suas ideias clarificadoras e out-of-the box. ${ }^{3}$

Uma revista médica é feita por pessoas, uma equipa que se quer competitiva, mas gerida de modo muito profissional, para jogar na primeira divisão internacional, aquela do Fator de Impacto. Foi também um modo de colocar à prova conhecimentos de gestão, negociação, motivação, liderança, gestão de conflitos, delegação e supervisão, gestão multitarefas, gestão de projetos; na realidade foi um cockpit de gestão em tempos difíceis. Mas sempre com o excelente apoio da Ordem dos Médicos, no fundo o patrão da revista. ${ }^{4} \mathrm{E}$ ainda fomos fazendo formação, publicando sobre o tema de como pesquisar e de como publicar. $^{5}$

Ter sido editor-chefe da AMP foi uma experiência fascinante, pela honra em vestir a camisola da Ordem dos Médicos, a qual, dada a sua imagem de marca excelente, nos abriu todas as portas para angariar artigos e publicar projetos de investigação das grandes instituições e hospitais portugueses.

$O$ editor-chefe, à semelhança do que acontece com outras grandes revistas generalistas deve ser uma figura nacional, uma voz livre e muitas vezes inconformada, representativa da boa ciência e da boa publicação científica.

A possibilidade de networking, mesmo a nível internacional, é excelente, e possibilitou-me o acesso a entidades e personalidades tão diversas quanto o New England Journal of Medicine (NEJM), British Medical Journal (The BMJ), The Lancet, Nigel Crisp, NICE, Springer Milan, o grupo Cochrane, Organização Mundial de Saúde, COPE, curso internacional em Oxford para editores-chefes, etc, etc.

Tivemos liberdade para criar novas seções como foi a de 'Pintura e Medicina', que nos permitiu contactar com grandes museus que nos disponibilizaram grandes obras, a Assembleia da República (sim, tem um património

1. Serviço de Gastrenterologia e Hepatologia. Hospital de Santa Maria. Centro Hospitalar de Lisboa Norte. Lisboa. Portugal.

$\triangle$ Autor correspondente: Rui Tato Marinho. ruitatomarinho@sapo.pt

Recebido: 06 de março de 2019 - Aceite: 06 de março de 2019 | Copyright @ Ordem dos Médicos 2019 
museológico de muito valor), museu Gulbenkian, Tate Gallery, o museu Mauritshuis ('A Lição de Anatomia do Dr. Nicolaes Tulp', de Rembrandt!), o museu Soares dos Reis ('Esperando o Sucesso', de Henrique Pousão, foi o primeiro quadro, dando o mote), museu Berardo, museu Júlio Pomar.

That's it: organizámos cinco simpósios sobre edição médica em que juntámos cerca de 20 revistas médicas portuguesas, criámos a secção Acta Médica Portuguesa Student com o apoio da Associação Nacional dos Estudantes de Medicina, renovámos o site, implementámos um novo sistema de submissão de artigos (Open Journal System), digitalizámos todos os números da revista desde 1979, recuperámos o atraso da publicação, a revista aumentou a sua periodicidade de $2 / 2$ meses para mensal, sai para o 'prelo' pontualmente (mas pontualmente) no final de cada mês, contratámos um designer profissional a tempo inteiro, o cargo de editor-chefe foi lançado a concurso e tem um perfil semi-profissional com 20 horas por semana. Ainda fomos sendo convidados para várias comunicações, palestras sobre o papel do editor-chefe, como funciona uma revista... Foram 35 vezes a falar sobre a $\mathrm{AMP}$, em vários pontos do País.

Foi uma oportunidade para conhecer por dentro a Ordem dos Médicos, os nossos Bastonários que marcaram o caminho de afirmação da revista (José Manuel Silva e

\section{REFERÊNCIAS}

1. Thomas L. The youngest science. Penguin Compass; 1983.

2. Bonhorst DH, Gracias R, Carvalho MG, Andrade ML, Tavares MA, Silva Pereira MF, et al. Estudo da especificidade da isoenzima MB da creatinaquinase na cirurgia cardíaca com circulação extra-corporal (fases pré, intra e pós operatória). Acta Med Port. 1979;1:3-14.

3. Smith R. The trouble with medical journals. London: The Royal Society
Miguel Guimarães). Foi um trabalho de puro voluntariado, reconhecido pela Medalha de Mérito da Ordem em 2015. O tempo despendido nessa altura era de cerca de um dia de trabalho por semana.

\section{Factos e números}

A AMP tem vindo a seguir o seu caminho. O número de artigos recebidos aumentou de cerca de 280 em 2011 para mais de 1100 . Mas a taxa de rejeição subiu para $85 \%$. É um índice de qualidade. AAMP já não é mais aquela revista onde é fácil publicar.

O Fator de Impacto tem vindo sempre a subir de forma paulatina.

De momento contabilizamos 3868 artigos na PubMed de acesso livre ao conteúdo integral. É um património.

A publicação tem sido contínua, desde há quatro décadas, agora em open access, mas sem custos para os autores, o que começa a não ser frequente nos tempos que correm. O autor e o seu artigo é, pois, o nosso cliente principal. E a vida do artigo começa depois da publicação.

\section{O futuro}

Crescer, crescer, de forma sustentável.

A Fake-Science, as revistas predatórias crescem como cogumelos, a má ciência disfarçada de qualidade é cada vez mais frequente. Necessitamos de revistas como a AMP.

Publish or Perish!

of Medicine Press; 2011.

4. Drucker P. The five most important questions you will ever ask about your organization. Leader to Leader Institute; 2008.

5. Donato H, Marinho RT. Dicas para escrever um título. Acta Med Port. 2015;28:269-70. 